\section{Radiological prevalence of Paget's disease in Dunedin, New Zealand}

Several recent surveys have shown regional variations in the prevalence of Paget's disease of bone. ${ }^{12}$ Although this condition is believed to be common in the elderly in New Zealand ${ }^{3}$ and many patients there receive treatment for it, ${ }^{4}$ its specific prevalence has not been measured in any New Zealand community. We therefore undertook a survey to determine the radiological prevalence of Paget's disease in subjects aged 55 or older living in Dunedin.

\section{Methods and results}

The prevalence of Paget's disease was assessed by examining abdominal radiographs of 500 men and 500 women aged 55 or older at the time of $x$ ray examination. Suitable films were chosen sequentially from those stored in the radiology department of Dunedin Hospital. The age of each patient at the time of $x$ ray examination was recorded. All radiographs included showed the entire pelvis and sacrum, the femoral heads, and all five lumbar vertebrae and had been taken during intravenous pyelography, barium studies, or plain abdominal examinations. Thus none of the films had been taken specifically to evaluate suspected skeletal disorders. Using conventional radiological criteria for the diagnosis of Paget's disease, ${ }^{1}$ a single observer (JR) initially classified each film as positive, doubtful, or negative for the disease. Subsequently, a second radiologist (LB) re-examined all positive and doubtful films $(n=53)$, which were then definitely classified ( 46 positive and seven negative) after discussion between JR and LB.

To assess within observer variation JR re-examined 125 films. Eighty five of these were selected randomly from the 947 radiographs classified initially as negative, while $\mathbf{4 0}$ were selected from the radiographs that had been classed as positive or doubtful. JR was unaware of her initial assessment of these films. None of the 85 films initially judged to be negative was reclassified. One film initially scored as positive, however, was regraded as negative, and two doubtful films initially classed as negative were reclassified as positive. In the context of the mix of radiographs examined in the survey this represented a within observer error of less than $1 \%$.

The table shows the age structure of the population surveyed and the number in each age group with evidence of Paget's disease. In Dunedin the prevalence, adjusted to the age-sex structure of the standard British population initially surveyed by similar methods, ${ }^{1}$ was $5.4 \%$ in men and $3.4 \%$ in women, giving an overall adjusted prevalence of $4 \cdot 4 \%$.

\section{Comment}

The survey confirmed that the prevalence of Paget's disease in middle aged and elderly people living in Dunedin is high. The prevalence after adjustment for age and sex $(4 \cdot 4 \%)$ is slightly less than that found in Great Britain using similar survey methods ${ }^{12}$ but greater than that reported in any other community, including examples from Australia, the United States, and several western European countries. ${ }^{1}$ The results accordingly substantiate the widely quoted anecdotal statement of Barry ${ }^{3}$ claiming a high prevalence of Paget's disease in New Zealanders.

Although New Zealand has a multiracial society, with about $12 \%$ of the population being either Maoris or Pacific Islanders, the proportion of these racial groups living in Dunedin is much smaller (less than $3 \%$ ), and there are even fewer Asians. Thus our results relate to the prevalence of Paget's disease in New Zealanders of European race. The disease is generally believed to be uncommon in Maoris ${ }^{3}$; this survey offers no evidence to support or refute this. The results, nevertheless, bring to attention the question of the pathogenesis of this disease, to which both environmental and genetic factors seem to contribute. ${ }^{5}$

We thank Professor D J P Barker for providing details of the age-sex structure of his initial survey population in Britain. Mr G F S Spears helped with statistical analysis of our data.

' Barker DJP, Clough PWL, Guyer PB, Gardner MJ. Paget's disease of bone in 14 British towns. Br Med $\mathcal{F} 1977 ; 1: 1181-3$.
2 Detheridge FM, Guyer PB, Barker DJP. European distribution of Paget's disease of bone. $\mathrm{Br}$ Med $\mathcal{F} 1982 ; 285: 1005-8$.

${ }^{3}$ Barry HC. Paget's disease of bone. London: Livingstone, 1969

${ }^{4}$ Ibbertson HK, Henley JW, Fraser TR, Tait B, Stephens EJ, Scott DJ. Paget's disease of bone-clinical evaluation and treatment with diphosphonate. Aust NZ F Med 1979;9:31-5.

5 Tilyard MW, Gardner RJM, Milligan L, Cleary TA, Stewart RDH. A probable linkage between familial Paget's disease and the HLA loci. Aust NZ F Med 1982;12:498-500.

(Accepted 22 March 1983)

Departments of Medicine and Radiology, University of Otago Medical School, Dunedin, New Zealand

J C REASBECK, MB, BS, registrar in radiology

A GOULDING, PHD, senior research officer in medicine

D R CAMPBELL, BSC, scientific officer in medicine

L R BEALE, FRCR, FRACR, clinical lecturer in radiology

R D H STEWART, MD, FRCP, professor in medicine

Correspondence to: Professor R D H Stewart, Department of Medicine, University of Otago, PO Box 913, Dunedin, New Zealand.

\section{Aluminium hydroxide intake: real risk of aluminium toxicity}

Our knowledge of aluminium toxicity has increased in recent years based on experience in patients receiving haemodialysis and exposed to aluminium in the water supply. The place of aluminium containing phosphate binders also merits attention, however, as a source of aluminium toxicity in patients receiving dialysis. ${ }^{12}$

\section{Patients, methods, and results}

To investigate the consequences of long term administration of aluminium hydroxide we measured the serum aluminium concentrations by electrothermal absorption spectrometry in 95 patients receiving long term haemodialysis. During the past three years we have monitored the aluminium concentration in the water supply every three to four months and used reverse osmosis water treatment in those patients with a tap water value higher than $1.0 \mu \mathrm{mol} / 1(2.7 \mu \mathrm{g} / 100 \mathrm{ml})$. We also noted the time spent on haemodialysis as well as the amount of aluminium hydroxide taken. Most patients used the capsule form (Alu-Cap) but some used Aludrox gel or tablets. Statistical analyses were by Student's $t$ test.

The patients were divided into three groups depending on their serum aluminium concentrations (table). The time spent on haemodialysis and the dose of aluminium hydroxide during the previous one and six months were related to the serum aluminium value. The total dose while receiving

Serum aluminium concentrations, time spent on haemodialysis, and dose of aluminium hydroxide in 95 patients receiving haemodialysis

\begin{tabular}{|c|c|c|c|c|}
\hline & & \multicolumn{3}{|c|}{ Serum aluminium $(\mu \mathrm{mol} / \mathrm{l})$} \\
\hline & & $<1.5$ & $1 \cdot 5-3 \cdot 0$ & $>3.0$ \\
\hline \multicolumn{2}{|c|}{ No of patients } & 19 & 40 & 36 \\
\hline \multicolumn{2}{|c|}{ Months of haemodialysis (SEM) } & $17(5)$ & $36(4)$ & $43(4)$ \\
\hline \multirow{3}{*}{$\begin{array}{l}\text { Aluminium } \\
\text { hydroxide } \\
\text { intake in } \\
\text { grams } \\
\text { (SEM) }\end{array}$} & Dose during past month & $8 3 \longdiv { ( 1 3 ) }$ & $96(8)$ & $121(9)$ \\
\hline & Dose during past 6 months & $5 1 9 \longdiv { ( 9 6 ) }$ & $608(42)$ & $729(54)$ \\
\hline & Total dose while on haemodialysis & $1627(504)$ & $3560(372)$ & $3911_{* * *}(461)$ \\
\hline
\end{tabular}

${ }^{*} \mathrm{p}<0.05 .^{* *} \mathrm{p}<0.01 . \quad{ }^{* * *} \mathrm{p}<0.001$

Conversion: SI to traditional units-Serum aluminium: $1 \mu \mathrm{mol} / 1 \approx 2.7 \mu \mathrm{g} / 100 \mathrm{ml}$

Prevalence of Paget's disease in radiographs of 1000 people in Dunedin

\begin{tabular}{|c|c|c|c|c|c|c|c|c|c|}
\hline Age (years): & $55-59$ & $60-64$ & $65-69$ & $70-74$ & $75-79$ & $80-84$ & $85-89$ & $\geqslant 90$ & Total \\
\hline $\begin{array}{l}\text { Men: } \\
\text { No assessed } \\
\text { No }(\%) \text { with Paget's disease }\end{array}$ & $\begin{array}{r}90 \\
0\end{array}$ & $\begin{array}{l}98 \\
3(3 \cdot 1)\end{array}$ & ${ }_{6}^{100}(6 \cdot 0)$ & 96 & $\stackrel{74}{9}(12 \cdot 2)$ & 29 & $\begin{array}{r}13 \\
0\end{array}$ & $\begin{array}{l}\mathbf{0} \\
\mathbf{0}\end{array}$ & 500 \\
\hline $\begin{array}{l}\text { No assessed } \\
\text { No }(\%) \text { with Paget's disease }\end{array}$ & $67(1.5)$ & 97 (4.1) & 99 & $\begin{array}{l}76 \\
4(5 \cdot 3)\end{array}$ & ${ }_{1}^{87}(1 \cdot 1)$ & $\stackrel{43}{3(7 \cdot 0)}$ & $\stackrel{16}{2(12 \cdot 5)}$ & 15 (6.7) & $\begin{array}{l}500 \\
17(3 \cdot 4)\end{array}$ \\
\hline
\end{tabular}


haemodialysis showed a higher correlation, as it combined the effect of dose and duration of rreatment.

\section{Comment}

That aluminium is implicated in dialysis encephalopathy and osteomalacic dialysis osteodystrophy has been shown convincingly in dialysis centres situated in areas with high water aluminium concentrations. ${ }^{34}$ Since the first reports an increasing number of renal units have begun to use water treatment and monitor the serum and water aluminium concentrations. With lessening of the risk of aluminium toxicity from the dialysate, attention has turned to the importance of aluminium containing phosphate binders.

We found a significant relation between the serum aluminium concentration and both the dose of aluminium hydroxide and length of time spent on dialysis. Most patients were also given aluminium hydroxide before dialysis but we were not able to analyse this. While it is still uncertain at what serum concentration bone toxicity occurs, bone aluminium content is increased in most patients receiving dialysis even with water treatment. Fifty four of the 59 patients reported on by Hodsman et al had raised bone aluminium concentrations despite the fact that water treatment was used by almost all of them. ${ }^{5}$ Thirty six of our patients had serum aluminium values above $3.0 \mu \mathrm{mol} / 1(8.0 \mu \mathrm{g} / 100 \mathrm{ml})$. Of these, 32 were over $4.0 \mu \mathrm{mol} / 1$ with a range of $4 \cdot 0-12 \cdot 3 \mu \mathrm{mol} / 1(10 \cdot 8-33 \cdot 2 \mu \mathrm{g} / 100 \mathrm{ml})$. These patients were certainly at risk of developing osteomalacia, and possibly also some of those with values below $3.0 \mu \mathrm{mol} / \mathrm{l}$. While no ideal phosphate binder has been described, serious consideration needs to be given to replacing aluminium hydroxide with a different compound or using smaller doses in conjunction with another agent.

${ }^{1}$ Berlyne GM, Ben-Ari J, Pest D, et al. Hyperaluminaemia from aluminium resin in renal failure. Lancet 1970;ii:494-6.

${ }^{2}$ Marsden SNE, Parkinson IS, Ward MK, Ellis HA, Kerr DNS. Evidence for aluminium accumulation in renal failure. Proc Eur Dial Transplant Assoc $1979 ; 16: 588-93$.

${ }^{3}$ Elliott HL, Dryburgh F, Fell GS, Sabet S, MacDougall AI. Aluminium toxicity during regular haemodialysis. Br Med f 1978;i:1101-3.

${ }^{4}$ Parkinson IS, Ward MK, Feest TG, Fawcett RWP, Kerr DNS. Fracturing dialysis osteodystrophy and dialysis encephalopathy. An epidemiological survey. Lancet $1979 ; \mathrm{i}: 406-9$.

${ }^{5}$ Hodsman AB, Sherrard DJ, Alfrey AC, et al. Bone aluminium and histomorphometric features of renal osteodystrophy. $\mathcal{F}$ Clin Endocrinol Metab $1982 ; 54: 539-46$.

(Accepted 7 April 1983)

Renal Unit, Western Infirmary, Glasgow G11 6NT

J B CANNATA, MD, research fellow (on attachment from the Hospital General de Asturias, Oviedo, Spain)

J D BRIGGS, MB, FRCP, consultant nephrologist

B J R JUNOR, MD, MRCP, consultant nephrologist

University Department of Pathological Biochemistry, Royal Infirmary, Glasgow

G S FELL, PHD, MRCPATH, reader

Correspondence to: Dr J B Cannata.

\section{Neuroleptic malignant syndrome}

The neuroleptic malignant syndrome is a rare but potentially lethal complication of neuroleptic drugs, characterised by muscular rigidity, hyperpyrexia, altered consciousness, and autonomic disturbance. Although numerous cases have been reported from France $^{1}$ and the United States, ${ }^{2}{ }^{3}$ there has been only a single British report. ${ }^{4}$ We describe a further case.

\section{Case report}

A 33 year old single man presented with a paranoid psychosis which had developed insidiously over two years and deteriorated rapidly the previous month. There was no notable past psychiatric, medical, or family history. He showed both first rank symptoms of schizophrenia and features of endogenous depression. Before admission he had been taking trifluoperazine (Stelazine) $5 \mathrm{mg}$ twice daily and dothiepin $75 \mathrm{mg}$ twice daily.

Examination showed a tall man $(193 \mathrm{~cm})$ weighing $105 \mathrm{~kg}$. Results of routine physical examination, full blood count, urea and electrolyte concen- trations, liver function values, and chest $x$ ray appearances were normal He was treated with chlorpromazine (up to $600 \mathrm{mg}$ daily) and haloperidol (up to $30 \mathrm{mg}$ daily). Procyclidine $10 \mathrm{mg}$ three times a day was added to counteract the extrapyramidal side effects.

The patient remained floridly psychotic and difficult to manage. Eight days after admission he appeared oversedated and the extrapyramidal side effects worsened. The neuroleptics were halved, and then stopped two days later. $\mathrm{He}$ developed hyperventilation, profuse sweating, dysphagia, dysarthria tachycardia, and a labile blood pressure and his conscious level fluctuated. Plantar reflexes were intermittently extensor.

He was transferred to a medical ward, where he developed fever up to $40 \cdot 2{ }^{\circ} \mathrm{C}$ and neck stiffness but showed no localising neurological signs Abnormal findings included a neutrophil leucocytosis of $17 \times 10^{9} / 1$, abnormal liver function values (serum aspartate transaminase activity $62 \mathrm{U} / 1$, lactate dehydrogenase activity $961 \mathrm{U} / 1$ ), raised creatine phosphokinase activity ( $373 \mathrm{U} / 1$ ), and raised blood urea concentration. Cerebrospinal fluid pressure was raised and protein concentration low, but otherwise the fluid was normal an electroencephalogram was also normal. Results of viral studies were negative. The differential diagnosis was meningitis or encephalitis, and when his condition deteriorated septicaemia was considered; blood cultures, however. were sterile, and antibiotics produced no improvement. A tentative diagnosis of the neuroleptic malignant syndrome was made, and two days after transfer, and despite intensive supportive measures, he died of cardiorespiratory failure. Postmortem examination showed evidence of longstanding cardiomyopathy and a large spleen.

\section{Comment}

This patient showed all the major features of the neuroleptic malignant syndrome. The syndrome has been described in association with butyrophenones, phenothiazines, and thioxanthenes, but haloperidol and depot fluphenazines are most commonly implicated. The onset of the syndrome may be within hours of the first dose of neuroleptic or after months of drug use, and some patients have been safely re-exposed to the drug. Some reported cases show evidence of preexisting organic brain disease, physical exhaustion, or dehydration.

The syndrome begins with severe extrapyramidal symptoms of rigidity and akinesia together with or shortly before the development of fever and autonomic disturbance. Consciousness fluctuates from alert mutism to stupor and coma. Once started, the syndrome develops rapidly over the 24-72 hours. Respiratory failure is the commonest cause of death. There is an overall mortality of $20 \%,{ }^{2}$ which is higher for depot than for oral neuroleptics. There are no specific or diagnostic laboratory findings, but leucocytosis, raised creatine kinase activity, and abnormal liver function values have been reported. ${ }^{3}$ The electroencephalogram is generally normal but may show non-specific slow wave activity. Cerebrospinal fluid, isotope brain scans, CT scans, and postmortem examinations (when performed) show nothing abnormal.

Neuroleptic malignant syndrome may be misdiagnosed as encephalitis or other infectious diseases affecting the nervous system. The syndrome has been compared with acute lethal catatonia described in the preneuroleptic era, and with malignant hyperpyrexia ${ }^{5}$ associated with inhalational anaesthetics and depolarising muscle relaxants.

The pathogenesis of the disorder is unknown, but dopamine receptor blockade in the basal ganglia and hypothalamus has been postulated. ${ }^{3}$ There is no known specific treatment, and it is essential to stop neuroleptic medication as soon as the disorder is recognised. Then supportive measures may be effective in preventing a fatal outcome.

We are grateful to Dr L Libman, Bromsgrove General Hospital, Dr Lynd Beeley and staff of the Drug Information Centre, Queen Elizabeth Hospital, and Dr B Fischer, Bromsgrove General Hospital, for their help in this case.

1 Delay J, Pichot P, Lemperiere T. Un neuroleptique majeur non phenothiazine et non reserpinique l'haloperidol dans le traitement des psychoses. Ann Med Psychol (Paris) 1960;118:145-52.

2 Caroff SN. The neuroleptic malignant syndrome. F Clin Psychiatry 1980; 41:79-83.

${ }^{3}$ Smego RA, Durack DT. The neuroleptic malignant syndrome. Arch Intern Med 1982;142:1183-5.

${ }^{4}$ Allen RC, White HC. Side effects of long-acting phenothiazines. Br Med $\mathfrak{F}$ $1972 ; \mathrm{i}: 221$.

${ }^{5}$ Britt BA. Aetiology and pathophysiology of malignant hyperthermia. Fed Proc 1979;38:44-8.

(Accepted 31 March 1981)

Barnsley Hall Hospital, Bromsgrove, Worcestershire B61 0EX ROSEMARIE V COPE, MB, MRCPSYCH, consultant forensic psychiatrist ELIZABETH M GREGG, MB, MRCPSYCH, senior registrar in psychiatry

Correspondence to: Dr R V Cope. 